\title{
Myxoma virus in the European rabbit: interactions between the virus and its susceptible host
}

\author{
Marianne M. StANFORD, Steven J. WeRdEN, Grant McFAdDEN* \\ Biotherapeutics Research Group, Robarts Research Institute and Department of Microbiology and \\ Immunology, University of Western Ontario, Siebens-Drake Building, Room 126, 1400 Western Road, \\ London, Ontario, N6G 2V4, Canada
}

(Received 9 March 2006; accepted 20 June 2006)

\begin{abstract}
Myxoma virus (MV) is a poxvirus that evolved in Sylvilagus lagomorphs, and is the causative agent of myxomatosis in European rabbits (Oryctolagus cuniculus). This virus is not a natural pathogen of $O$. cuniculus, yet is able to subvert the host rabbit immune system defenses and cause a highly lethal systemic infection. The interaction of MV proteins and the rabbit immune system has been an ideal model to help elucidate host/poxvirus interactions, and has led to a greater understanding of how other poxvirus pathogens are able to cause disease in their respective hosts. This review will examine how MV causes myxomatosis, by examining a selection of the identified immunomodulatory proteins that this virus expresses to subvert the immune and inflammatory pathways of infected rabbit hosts.
\end{abstract}

myxoma virus / immunomodulation / poxvirus / Oryctolagus cuniculus

\section{Table of contents}

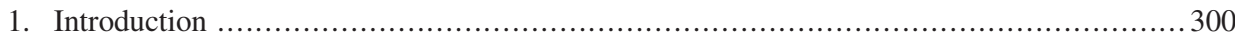

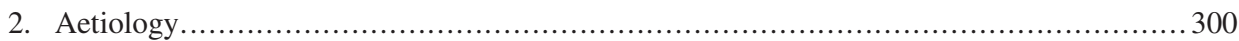

3. Epidemiology and clinical signs of myxomatosis ................................................. 301

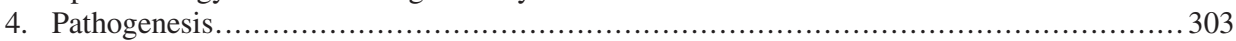

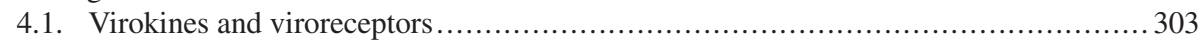

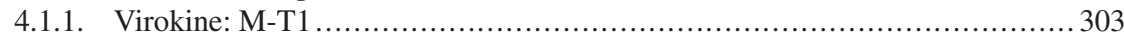

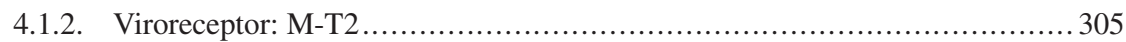

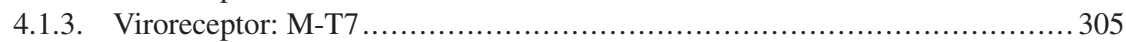

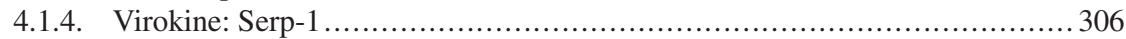

4.1.5. Virokine: Myxoma Growth Factor (M010L) .................................... 306

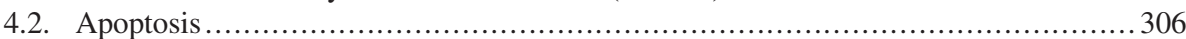

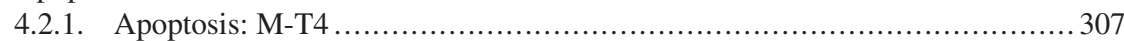

4.2.2. Apoptosis: M-T5 ............................................................... 307

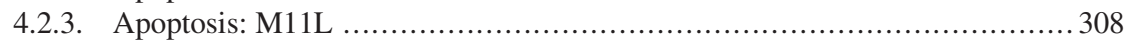

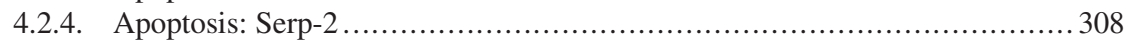

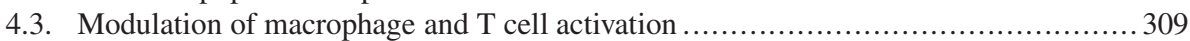

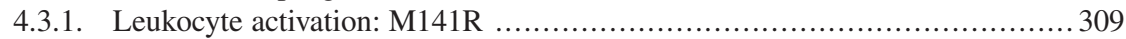

4.3.2. Leukocyte activation: M128L ............................................ 310

* Corresponding author: mcfadden@ robarts.ca 


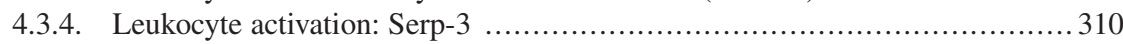

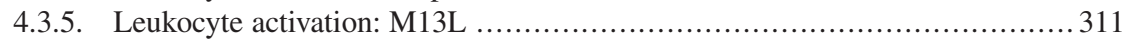

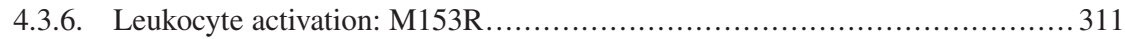

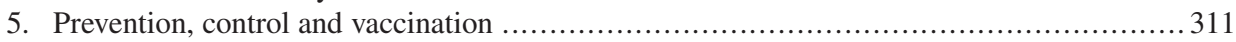

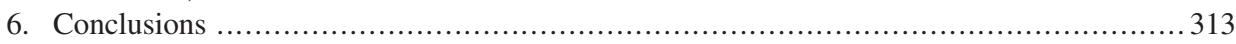

\section{INTRODUCTION}

Myxoma virus (MV) causes the debilitating disease known as myxomatosis in domesticated European rabbits. This virus is a member of the Leporipoxvirus genus and the Chordopoxvirinae subfamily of Poxviridae. It was first described by Sanarelli in 1896 in South America as the causative agent of a lethal infection in imported European rabbits (Oryctolagus cuniculus). Subsequent work determined MV to be a natural pathogen of the South American tapeti (Sylvilagus brasilensis), and of the North American brush rabbit (Sylvilagus bruneii) with MV strains endemic of these areas being designated the Brazilian and Californian strains, respectively [31]. In its evolutionary Sylvilagus hosts, this virus causes only a benign infection, characterized by a cutaneous fibroma restricted to the site of the inoculation. However, in European rabbits, virus infection causes the rapid systemic and lethal infection that has mortality rates at nearly $100 \%$ [30].

The introduction of the European rabbit to Australia in 1859 has had a devastating effect on the biodiversity of that continent. In 1918, Aragão, who was involved in much of the initial characterization of MV, formally suggested using this virus to curb the feral rabbit population. After thorough investigation, MV was used as a biological control in 1950, when the Standard Laboratory Strain (SLS), also known as the Moses strain, isolated in Brazil in 1911, was released into the wild. In 1952, a similar strain known as Lausanne, isolated in Brazil in 1949, was illegally released into
Europe by a landowner hoping to curb the rabbit population of his property. The subsequent rapid coevolution of both host and virus has been well documented [29]. The result has been the selection of both dramatically attenuated field variants of MV, and an increasingly resistant population of rabbits present in Australia [8].

The entire genome of myxoma virus strain Lausanne has been sequenced, and many of both the structural proteins and immunomodulatory proteins have been characterized $[5,11]$. There are many extensive and excellent reviews on the immunomodulatory proteins of poxviruses $[42,50,64,69,74,75,87,91$, 106]. This review will focus primarily on the interactions of MV and its susceptible host, the European rabbit in vitro and in vivo.

\section{AETIOLOGY}

MV is a member of the Poxviridae family, and the prototypic member of the Leporipoxvirus genus. Poxviruses are all large, linear double stranded DNA viruses that have the capacity to infect both invertebrates (Entomopoxvirinae) and vertebrates (Chordopoxvirinae). Poxviruses also have a classic brick shaped virion and replicate exclusively in the cytoplasm of infected cells. Poxviruses have the ability to cause both acute and persistent infections, yet no poxvirus has been shown to integrate its DNA into the host genome, or undergo a true latent stage infection [68].

Poxviruses are larger than most animal viruses with dimensions in the order of 
several hundred nanometers, and can be observed by light microscopy [68]. The sequence of MV revealed it to have $161.8 \mathrm{kB}$ of DNA, encoding 171 unique genes [11]. The central portion of the genome encodes close to 100 genes that are among the highly conserved set of conserved poxviral genes, encoding mostly structural and housekeeping functions, while the ends have terminal inverted repeats (TIR) and closed hairpin looks at each end [32, 34]. These TIR and the near-terminal unique regions of the poxvirus genome are where many immunomodulatory genes involved in subverting the host immune system map. A selection of these host-interaction proteins of MV will be discussed in the next section.

Poxviruses are enveloped viruses, and have at least two distinct forms that can productively infect cells - the intracellular mature virus (IMV) and the extracellular enveloped virus (EEV). These two forms differ in their membrane components and are thought to enter cells by different mechanisms [88, 101, 102]. Although there have been multiple viral proteins that have been shown to be essential for virus entry/fusion into cells [70], the cellular determinants for poxvirus binding are believed to be the ubiquitously expressed surface glycosaminoglycans or extracellular matrix proteins $[15,18]$. After virus binding to cellular membranes, there is a fusion step that is generally poorly understood, yet results in the release of the virion core into the cytoplasm of the cell [70]. The viral transcriptosome is in the released core, containing the endogenous RNA polymerase and transcription factors. It initiates the first wave of early viral gene transcription, synthesizing viral mRNA under the control of early viral promoters. This stimulates the second uncoating stage, releasing the viral DNA into the cytoplasm where it can serve as a template for viral DNA replication and the subsequent intermediate and late tran- scription of poxviral genes. As late viral gene products accumulate, the virus undergoes morphogenesis and assembly of infectious virus particles. The first infectious forms that appear are the intracellular mature virions (IMV) which travel along microtubules and then become enwrapped in Golgi-derived membranes to form intracellular enveloped virus or IEV [83]. However, early tubular endosomes have also been shown to contribute to IEV formation [100]. As the IEV fuses with the cellular membrane, it loses a membrane wrapping to form the cell associated enveloped virus, or $\mathrm{CEV}$, an important component of cell to cell infection, as this virus is propelled into the neighboring cell via actin tail formation, or can be released from the cell as EEV. Whereas CEV and EEV are important in cell to cell spread in vivo, IMV infection becomes important in virus spread after cell death and membrane rupture [89, 104].

In addition to the numerous poxviral proteins involved in propelling the virus through its replication cycle, these viruses also encode an additional plethora of proteins that allow them to survive in the harsh environment of the host. These include expressing inhibitors of the antiviral pathways of the cell, preventing the cell death of the infected cell and the encoding anti-inflammatory proteins to dampen the host defenses mounted against it. These immunomodulatory proteins often mediate pathogenesis induced by these viruses [87] and some will be discussed in greater detail in the next sections.

\section{EPIDEMIOLOGY AND CLINICAL SIGNS OF MYXOMATOSIS}

Today, MV is endemic on four continents: North and South America, Europe and Australia [20]. In much of South America, such as Brazil and Uruguay, the virus is endemic in rabbits of the 
Sylvilagus genus, particularly S. brasiliensis. However, in countries such as Chile, the principal reservoir is the wild European rabbit (O. cuniculus). On the contrary, in North America, the Californian strain of MV is endemic to wild Sylvilagus rabbits in the area, particularly S. bachamani and this species serves as a reservoir of infection for domestic rabbits. In Australia, the virus has been endemic in the wild European rabbit population since its introduction in 1950. In Europe, myxomatosis has spread to many countries after its initial introduction in 1952, with $O$. cuniculus being the predominant host species. However, other lagomorphs such as the European hare (Lepus europaeus), the mountain hare (Lepus timidus) and other Sylvilagus species can also serve as hosts [20].

The clinical signs of myxomatosis vary widely among the evolutionary and susceptible lagomorph hosts. In members of the Sylvilagus species, infection usually results in the formation of localized skin pseudo-tumors at the site of virus infection. These tumors resemble fibromas and usually appear 4-8 days after exposure, and may persist for up to 40 days [46]. Young Sylvilagus rabbits may succumb to a generalized disease following infection with MV [31].

Myxomatosis in European rabbits is much more severe and results in a high mortality rate. The severity of the clinical disease can differ with the strain of MV used, as well as the strain of rabbit infected. To date, there are at least two forms of myxomatosis in European rabbits; the nodular or typical form of myxomatosis and amyxomatosis or "atypical" myxomatosis. The main difference between these forms is that the latter is characterized by having highly reduced cutaneous clinical signs and is typically classified by intense respiratory distress in the atypical form of the disease [60-62]. This increased lethality of this type of myxomatosis may be due to severe immunopathology (i.e. toxemia or cytokine storm) induced by the virus in its host.

The clinical signs and high mortality rates associated with myxomatosis are believed to be a result of multi-organ dysfunction as well as uncontrolled secondary bacterial infections of the respiratory tract that result from the progressive impairment of the host immune response [29,31, $32,68]$. The early clinical signs of typical myxomatosis are swelling of the muzzle and anogenital region, as well as blepharoconjuctivitis $[29,32,68]$. This gives the rabbit a leonine-like appearance. The severity of clinical disease can vary between different strains of rabbits as well as MV isolates. The variety of clinical signs have been extensively reviewed elsewhere [2729].

In general, Californian strains of myxoma virus are quite pathogenic. Animals can die within a week of infection, with little clinical signs other than edema and lethargy. Animals that survive 1-2 weeks exhibit more inflammation, edema and skin hemorrhages. Rabbits infected with Brazilian strains (such as the South American Moses strain) usually survive for 10-14 days and subcutaneous gelatinous swellings (from which the name myxomatosis was derived) appear all over the body. Typically, MV replicates in the skin at the site of infection and spreads from there into the draining lymph node. MV then replicates in the node to high titers and spreads via infected leukocytes to distal tissues such as the spleen, testis, lung, nose, conjunctivae and skin $[8,26]$. The formation of myxomas has not been reported with all strains of virus and may contribute to the two classified forms of the disease [20]. By the 10th day, hard convex lumps appear, and the primary lesion has become necrotic, whereas the secondary lesions may also become necrotic in rabbits surviving over two weeks. Infected rabbits usually live $8-15$ days, and death is often preceded by terminal convulsions. 
Not all myxoma strains are lethal in the European Rabbit. The laboratoryattenuated neuroMV produces a mild disease with little or no mortality [20]. In both Australia and Europe, attenuated MV strains have emerged with lower morbidity and mortality [9]. These naturally attenuated strains, including the Urrarria strain in Australia produce flat rather than convex lesions and generally have a much lower mortality rate in susceptible European rabbits [9].

\section{PATHOGENESIS}

The pathogen-host relationship between MV and the European rabbit has been well characterized $[46,48]$ and is an excellent model to study the mechanisms by which a large DNA virus can use its genetic repertoire to manipulate the host immune response during viral infection. Successful viral replication can be attributed to the ability of the MV to avoid recognition and clearance by the host innate and acquired immune systems of the infected rabbit [47, 87]. A wide variety of MV encoded immunoregulatory proteins have been identified which include; virokines, viroreceptors, proteins that modulate host range and/or apoptotic response and proteins that modulate the action of macrophages and T cells (Tab. I). The proteins discussed do not represent all MV immunomodulator proteins, yet give a cross section of the scope of proteins encoded by this virus, and are the MV proteins most extensively characterized in both in vitro and in vivo studies. These particular MV proteins have been experimentally shown to function as critical virulence factors necessary for the infection and replication of MV leading to the development of myxomatosis in European rabbits.

\subsection{Virokines and viroreceptors}

Throughout evolutionary history poxviruses have continuously evolved, consequently developing a variety of sophisticated strategies to ensure successful viral replication within the host $[38,69,91]$. One particular mechanism conceived by MV to subvert the host immune response is carried out by two related sets of immunomodulatory proteins described as virokines and viroreceptors $[74,87]$. These virus-encoded proteins target specific pathways of the host immune system used to coordinate antiviral and early inflammatory responses directed against viral infection $[64,74]$. Viroreceptors closely resemble cellular receptors and are often secreted or expressed on the surface of virus infected cells [65]. They functionally bind and inhibit extracellular host ligands which are intended to induce an inflammatory or antiviral response following virus infection [42]. On the contrary, virokines are normally secreted and are often similar to host immune ligands such as cytokines, or chemokines, but usually the viral versions are smaller or have alternative biological properties compared to the host ligands $[54,64,90]$. Examples of myxoma encoded secreted immunomodulatory proteins include the following: (1) M-T1, an inhibitor of CC-chemokines; (2) M-T2, a tumor necrosis factor receptor homolog; (3) M-T7, a homolog of the interferongamma receptor; (4) Serp-1, a secreted serine proteinase inhibitor; (5) myxoma growth factor, ligand for the erbB family of EGF receptors.

\subsubsection{Virokine: $M-T 1$}

The MV glycoprotein M-T1 is a member of a large poxvirus family of secreted chemokine-binding proteins [50, $55,105]$. Two copies of the M-T1 gene are present in the TIR of the genome and the secreted protein has a molecular mass of $43 \mathrm{kDa}$ [52]. Chemical crosslinking demonstrated that M-T1 interacts with a broad spectrum of both CXCand $\mathrm{CC}$-chemokine subfamilies; with a 
Table I. Selected immunomodulatory proteins of MV.

\begin{tabular}{|c|c|c|c|c|c|}
\hline \multirow{2}{*}{ ORFs } & \multirow{2}{*}{ Gene name } & \multirow{2}{*}{ Protein function and/or properties } & \multicolumn{2}{|c|}{ Required for infection } & \multirow{2}{*}{ Reference(s) } \\
\hline & & & In vitro & In vivo & \\
\hline & & Virokines and viroreceptors & & & \\
\hline M001 L/R & M-T1 & $\begin{array}{l}\text { Chemokine binding protein; inhibits } \\
\text { chemokine chemoattractant properties }\end{array}$ & No & No & {$[35,51,52]$} \\
\hline M002 L/R & M-T2 & $\begin{array}{l}\text { TNF receptor homolog; binds rabbit } \\
\text { TNF- } \alpha\end{array}$ & $\begin{array}{l}\text { Only } \\
\text { RL-5 }\end{array}$ & Yes & $\begin{array}{l}{[58,84-86,} \\
97]\end{array}$ \\
\hline M007 L/R & M-T7 & $\begin{array}{l}\text { IFN- } \gamma \text { receptor homolog; also binds } \\
\mathrm{C}-\mathrm{C} \text { and } \mathrm{C}-\mathrm{X}-\mathrm{C} \text { chemokines in vitro }\end{array}$ & No & Yes & $\begin{array}{l}{[10,49,71,} \\
72,98]\end{array}$ \\
\hline $\mathrm{M} 008.1 \mathrm{~L} / \mathrm{R}$ & SERP-1 & Secreted serpin & No & Yes & {$[57,96]$} \\
\hline \multirow[t]{2}{*}{ M010L } & MGF & EGF-like growth factor & No & Yes & {$[78,79]$} \\
\hline & & Anti-apoptotic factors & & & \\
\hline M004 L/R & M-T4 & ER-localized apoptosis regulator & $\begin{array}{l}\text { Only } \\
\text { RL-5 }\end{array}$ & Yes & $\begin{array}{l}{[6,39,76,} \\
77,106]\end{array}$ \\
\hline M005 L/R & M-T5 & $\begin{array}{l}\text { Ankyrin-like host range; Cell } \\
\text { cycle/apoptosis inhibitor }\end{array}$ & $\begin{array}{l}\text { RL-5, } \\
\text { cancer } \\
\text { cells }\end{array}$ & Yes & {$[44,73,93]$} \\
\hline M11L & M11L & $\begin{array}{l}\text { Integral membrane protein/apoptosis } \\
\text { regulator }\end{array}$ & $\begin{array}{l}\text { Only } \\
\text { RL-5 }\end{array}$ & Yes & $\begin{array}{l}{[21,24,78} \\
92,103]\end{array}$ \\
\hline \multirow[t]{2}{*}{ M151R } & SERP-2 & Intracellular serpin & No & Yes & {$[67,80]$} \\
\hline & & Immune modulators & & & \\
\hline M141R & $\begin{array}{l}\mathrm{vOx}-2 \\
/ \mathrm{vCD} 200\end{array}$ & $\begin{array}{l}\text { Immunoglobulin domain/OX-2 } \\
\text { homolog }\end{array}$ & No & Yes & {$[11,12]$} \\
\hline M128L & vCD47 & $\begin{array}{l}\text { Integrin-associated protein, CD47 } \\
\text { homolog }\end{array}$ & No & Yes & {$[11,13]$} \\
\hline M150R & MNF & $\begin{array}{l}\text { Ankyrin-like/host range, inhibits } \\
\text { NF-אB }\end{array}$ & No & Yes & {$[11,14]$} \\
\hline M013L & M13L & $\begin{array}{l}\text { Pyrin-containing inhibitor of the } \\
\text { inflammasome }\end{array}$ & $\begin{array}{l}\text { Only } \\
\text { RL-5 }\end{array}$ & Yes & [43] \\
\hline M152R & Serp-3 & Virulence factor, viral serpin & No & Yes & [36] \\
\hline M153R & MV-LAP & $\begin{array}{l}\text { Promotes downregulation of MHC-I } \\
\text { and CD4 on T cells }\end{array}$ & No & No & {$[37,59]$} \\
\hline
\end{tabular}

preferentially higher affinity towards $\mathrm{CC}$ chemokines [35]. Therefore, M-T1 functions to effectively sequester soluble host chemokine ligands from binding their cognate cell-surface receptors in vitro, consequently inhibiting chemoattractant activities [51]. No significant difference in viral replication levels or the overall mor- tality rate of European rabbits infected with recombinant MV bearing the disrupted M-T1 genes (vMyxT1KO) was identified when compared to rabbits infected by the wild-type strain. The M-T1 gene is thus dispensable for a productive virus infection. However, during the first few days post infection an increase in the 
localized cellular infiltrate was observed in the deep dermal tissues surrounding the site of primary infection of vMyxT1KO infected rabbits. Leukocytes such as monocytes/macrophages were present in the infiltrate although these phagocytes were ineffective at clearing the virus infection [52]. Therefore, the functional role of $\mathrm{M}-\mathrm{T} 1$ is to bind and sequester chemokines responsible for the recruitment and activation of leukocytes during early stages of MV infection in susceptible rabbits.

\subsubsection{Viroreceptor: $M-T 2$}

The MV gene M-T2 was the first identified viroreceptor based on similar sequence homology to the N-terminal ligandbinding domain of cellular tumor necrosis factor (TNF) receptors [97]. M-T2 is a glycosylated protein, expressed as monomeric and dimeric species that are secreted from virus infected cells, and both have been demonstrated to bind rabbit specific TNF with an affinity similar to the rabbit TNF receptor $[84,85]$. However, the dimeric form of M-T2 was shown to be a more potent inhibitor of TNF cytolytic activities, presumably due to an increased ability to prevent TNF receptor signaling in response to the TNF trimer [86]. Rabbit T lymphocytes (as represented by the $\mathrm{CD}^{+}{ }^{+}$T-cell line RL-5) underwent extensive cellular apoptosis following infection by MV deficient in M-T2 (vMyxT2KO), therefore M-T2 also functions to block apoptosis. The addition of exogenous M-T2 protein to vMyxT2KO infected RL-5 cells was unable to inhibit cellular apoptosis in response to viral infection, suggesting that M-T2 inhibits apoptosis intracellularly [58]. Disease progression in susceptible rabbits is considerably attenuated when rabbits have been infected with vMyxT2KO in contrast to the parental virus strain [97]. The majority of vMyxT2KO infected rabbits made a full recovery, and when the survivors were subsequently challenged with wild type MV, they were resistant to developing myxomatosis [97]. Thus, both in vitro and in vivo studies conclude that the M-T2 gene is an essential virulence factor of $\mathrm{MV}$, necessary for successful disease progression in susceptible rabbits resulting in myxomatosis.

\subsubsection{Viroreceptor: $M-T 7$}

The most abundantly secreted protein from MV-infected cells, M-T7, has significant sequence similarity to the human and mouse receptors for interferongamma (IFN- $\gamma$ ) [71]. M-T7 was initially identified to specifically bind to and inhibit the biological activity of extracellular rabbit IFN- $\gamma$ [98]. Later binding studies indicated that purified M-T7 protein also interacts with representative members of the $\mathrm{CXC}-, \mathrm{CC}-$, and C-chemokine families by targeting the conserved C-terminal heparin-binding domain present on many cytokines [49]. In addition, M-T7 may functionally disrupt chemokine-glycosaminoglycan (GAG) interactions within virus-infected cells, leading to the interruption of important chemokine gradients [10]. Virus replication in cultured cells is unaffected by recombinant MV disrupted in both copies of the M-T7 gene (vMyxT7KO) but in vivo the M-T7 gene is required for a productive viral infection and it is a critical virulence factor for virus pathogenesis in the European rabbit [72]. In comparison to rabbits infected by the wild-type virus, a dramatic decrease in the clinical signs of myxomatosis and viral dissemination into secondary sites was observed in the vMyxT7KO infected rabbits. In addition, rabbits infected by the M-T7 knockout virus were characterized by an increase in the number of infiltrating leukocytes that migrate into the virus-infected lesions. 
An extensive number of lymphocytes in the secondary immune organs, particularly the spleen and lymph nodes, appeared to be activated as early as four days post infection [72]. In summary, M-T7 functions to modify the inflammatory cellular trafficking of lymphocytes into secondary lymphoid organs by binding and neutralizing host IFN- $\gamma$, and possibly destabilizing the local chemokine gradients, at the site of infection. The actions of M-T7 effectively disrupt the connection between antigen presenting cells of the infected tissue and the effector lymphocytes of the secondary lymphoid organs.

\subsubsection{Virokine: Serp-1}

The MV glycoprotein serpin 1 (Serp-1) is a $55 \mathrm{kDa}$ secreted protein, which functions as an irreversible inhibitor of serine proteases [96]. Serp-1 interacts with and inhibits, among others, plasmin, urokinase, and tissue-type plasminogen activator [19, 53]. However, many of these serine proteases were identified through human studies and little is know how Serp-1 interacts with similar proteins in the rabbit. Rabbits infected with MV deficient in Serp-1 (vMyxSerp1KO) suffered moderate clinical signs of myxomatosis but the disease was unable to progress to later stages. The majority of infected rabbits showed significant recovery within 14 days post infection and when re-challenged with the parental myxoma strain, were resistant to myxomatosis [57]. Significant tissue damage in the vMyxSerp1KO infected rabbits was observed in histological studies which included infiltration of mononuclear cells and a pronounced inflammatory response. The clinical signs, however, were less severe compared to rabbits infected with the wild-type virus [57]. Therefore, Serp-1 is an essential virulence factor and its functional role in preventing the infiltration of monocytes into the primary lesion is crit- ical for virus survival in infected rabbits, leading to myxomatosis.

\subsubsection{Virokine: Myxoma Growth Factor (M010L)}

M010L, also known as myxoma growth factor (MGF), is a secreted glycoprotein, which shares significant sequence similarity to members of the epithelial growth factor (EGF) family of proteins. In vitro studies have demonstrated that MGF is a non-essential factor for successful virus replication in rabbit spleen cells [78]. In vivo, however, the MGF gene is an essential virulence factor, such that viral replication was severely attenuated in rabbits infected with MV deficient in the MGF gene (vMyxMGFKO). A majority of the rabbits infected never became seriously ill and were resistant to myxomatosis when re-challenged by wild-type MV [78]. Full disease progression was observed in rabbits infected with vMyxMGFKO when either vaccinia virus growth factor, Shope fibroma growth factor (SFGF) or rat transforming growth factor alpha was used to restore the function of MGF in the knockout virus [79]. MGF therefore is required for MV replication in vivo but the mechanism of its role in pathogenesis remains to be better clarified.

\subsection{Apoptosis}

Apoptosis is a regulated process of cellular death used to remove unwanted or damaged cells while causing minimal disruption to surrounding tissues [45]. In response to virus infection, cells initiate apoptosis which is therefore a critical hostprotective mechanism for limiting virus infection and replication within the host [25]. Apoptosis is generally accompanied by the release of cytochrome $\mathrm{c}$ and other proapoptotic regulators from the mitochondria 
and the activation of caspases. This leads to a series of downstream events ultimately resulting in the digestion of key structural proteins in the cytoplasm and degradation of chromosomal DNA. Viruses with larger genomes, such as poxviruses, have evolved immunomodulatory proteins which function to inhibit host-cell apoptotic responses during early stages of viral infection [74, 94]. These anti-apoptotic effectors have been shown to manipulate the cell death pathways within the cell in a variety of ways, including the inhibition of caspases and disruption of key mitochondrial checkpoints to prevent apoptosis [22, 23, 94]. Therefore, the interaction between viral proteins and host apoptotic pathway is essential for MV to successfully replicate in the European rabbit. Examples of $\mathrm{MV}$-encoded proteins which regulate apoptosis in response to MV infection include the following: (1) M-T4, (2) M-T5, (3) M11L and (4) Serp-2.

\subsubsection{Apoptosis: M-T4}

M-T4 was identified as the first intracellular virulence factor in MV that functions from within the endoplasmic reticulum (ER) of infected cells [6]. Like most proteins specifically localized to the ER, M$\mathrm{T} 4$ posses a C-terminal ER-retention motif (RDEL) predicted to be critical for retrieval and retention of M-T4 in the ER [6]. However, removal of the RDEL motif from M-T4 did not affect localization of the protein within the ER, but the stability of the mutant protein was reduced [39]. MT4 was determined to have a functional role as an anti-apoptotic protein when cultured rabbit lymphocytes infected with $\mathrm{M}$ T4 knockout mutant virus (vMyxT4KO) underwent extensive apoptosis. Rabbits infected with M-T4 knockout virus resulted in disease attenuation, and recovered fully within 10 to 21 days post infection [6]. The number of secondary lesions on the infected animals was greatly reduced sug- gesting vMyxT4KO is unable to spread in vivo. Reduced virulence in infected rabbits may be due to the low number of infected $\mathrm{T}$ lymphocytes available to carry virus to distal lymph nodes [6]. The mechanism by which M-T4 protects infected cells against apoptosis from within the ER remains poorly understood. Rabbits infected with a recombinant M-T4 $\mathrm{RDEL}^{-}$ mutant virus suffered a novel form of myxomatosis, which was characterized by an exaggerated inflammatory response at the secondary sites of infection, particularly the ears [39]. Therefore M-T4 may have a dual function in protecting infected lymphocytes from apoptosis and in modulating the inflammatory response to virus infection.

\subsubsection{Apoptosis: $M-T 5$}

M-T5 is an ankyrin-repeat containing protein that possesses no significant sequence homology to non-viral proteins but is a member of a larger poxviral superfamily implicated in the determination of host range [73]. RL-5 cells or primary lymphocytes infected with M-T5 deficient MV (vMyxT5KO) failed to result in successful viral replication, however, the same mutant virus replicated with wild-type kinetics in rabbit fibroblasts [73]. Therefore, M-T5 is capable of extending the tissue specificity of MV to cells of lymphoid origin. When RL-5 T cells were infected with M-T5 knockout virus they underwent an extensive cellular apoptotic response as well as rapid inhibition of both host and viral genes [73]. It has been suggested that M-T5 is essential for cells infected with myxoma to overcome cell cycle arrest induced by viral infection, protecting cells from activating diverse cell death pathways resulting in apoptosis [44]. M-T5 was demonstrated to be a cell cycle regulatory protein by direct interaction with cullin-1, a cellular E3 ubiquitin ligase which enhances the proteasomal 
degradation of cell cycle regulators such as CDK-1 p27 Kip [44]. Similarly to the in vitro studies, susceptible laboratory rabbits infected with vMyxT5KO lacked progression of the infection past the primary site of inoculation, in addition to the establishment of a rapid and effective inflammatory reaction. The M-T5 knockout virus was unable to initiate a cellular reaction within secondary immune organs [73]. According to these observations, the M-T5 protein permits virus spread via infected lymphocytes that traffic to multiple distal sites and therefore functions as an essential virulence factor in the establishment of myxomatosis in the European rabbit.

\subsubsection{Apoptosis: $M 11 L$}

The MV protein M11L has no well defined structural motifs except a unique 25 amino acid long C-terminal sequence that forms a putative transmembrane domain similar to those present in anti-apoptotic Bcl-2 family members [21]. M11L is specifically localized in the mitochondria where it inserts into the outer membrane and is exposed to the cytoplasmic face of the organelle in MV-infected cells [21]. In vitro studies have identified $\mathrm{M} 11 \mathrm{~L}$ as a functional anti-apoptotic protein that prevents the loss of mitochondrial membrane potential, which accompanies cell death, by blocking staurosporine-induced apoptosis [24]. Based on cross-linking studies, M11L forms an inhibitory complex with the peripheral benzodiazepine receptor (PBR), a pro-apoptotic protein located on the outer mitochondrial membrane. It is through this interaction that M11L specifically blocks apoptosis induced by ligands of PBR. Deletion of the M11L C-terminus abolished the functional interaction between PBR and M11L, indicating that localization of $\mathrm{M} 11 \mathrm{~L}$ to the mitochondria is critical for its activity [24]. In addition, M11L has been shown to interact with the pro-apoptotic proteins Bak [103] and Bax [92], both Bcl-2 family members that are constitutively present on the mitochondria. Deletion of the M11L gene from MV completely abrogated the ability of the virus to cause the characteristic disease clinical signs associated with myxomatosis in susceptible rabbits [78]. All rabbits infected with the M11L knockout virus recovered completely by day 40 post infection and when challenged with wild-type MV, were found to be resistant to developing myxomatosis. However, despite the reduced virulence of the recombinant virus, lesions produced by the virus were larger and histological analysis revealed signs of vigorous inflammatory activity but regressed 30 days after infection [78]. In conclusion, the M11L gene product is an important virulence determinant for myxoma infection, modulating apoptosis, induced by virus infection, by multiple independent strategies that contribute to the blockade of apoptosis in the mitochondria.

\subsubsection{Apoptosis: Serp-2}

MV encodes an intracellular viral serpin (Serp-2) which has a molecular mass of $34 \mathrm{kDa}$ and is a member of the serpin superfamily [80]. In culture, both rabbit fibroblasts and rabbit $\mathrm{CD} 4^{+} \mathrm{T}$-cells supported replication of a Serp-2 knockout mutant MV (vMyxSerp2KO) with wildtype kinetics [67]. Serp-2 is, however, an essential MV virulence factor, and the majority of rabbits infected with the Serp-2 knockout virus only developed moderate clinical signs of myxomatosis and recovered completely within 30 days post infection. Histological examination revealed extensive inflammation in response to infection by the Serp-2 mutant virus in contrast to wild-type MV. In addition, rapid apoptosis was evident in the lymph node lymphocytes of the vMyxSerp2KO infected rabbits [67]. Therefore, Serp-2 is a virulence factor that is critical for the 
development of myxomatosis by inhibiting host inflammatory processes and by the prevention of apoptosis in lymphocytes, thus enabling them to spread to secondary sites of infection. Compared to CrmA, the prototypic poxvirus serpin encoded by cowpox virus, MV Serp-2 is a weak inhibitor of human interleukin-1 $\beta$ (IL-1 $\beta$ )converting enzyme (ICE) and granzyme B in vitro [80, 95]. Both Serp-2 and CrmA are functionally similar in vivo, however, when Serp-2 was tested for its ability to replace CrmA in cowpox virus-infected cells, Serp-2 was unable to inhibit apoptosis. The results indicate that Serp-2 and CrmA function differently in vitro [95]. Further studies are needed to determine if Serp-2 has a similar inhibitory function during MV infection in the rabbit.

\subsection{Modulation of macrophage and $T$ cell activation}

The activation of both the innate and acquired branches of the immune response is critical for viral clearance. To evade such a response, MV has developed strategies to specifically inhibit the activation of cells important in the initiation and propagation of both resident and recruited leukocytes. The resident macrophages are an important first line of defense against invading pathogens, and have the ability to rapidly express and secrete a plethora of cytokines and chemokines that act as danger signals to surrounding tissues. T cells are educated in the lymph nodes in the proximity of infection, and travel to the site of infection to produce crucial mediators and to directly kill virus infected cells in what is known as the cell mediated immune response. In addition to inhibiting the efficacy of secreted mediators by the production of virokines and viroreceptors, MV also directly targets the ability of leukocytes to become activated. It does this through the production of viral proteins that both mimic host factors that are important for their activation, and potentially sending conflicting signals, preventing the successful activation of these cells. These MV proteins include the following: (1) M141R (vCD200), (2) M128L (vCD47), (3) M150R (myxoma nuclear factor), (4) Serp-3, (5) M13L and (6) M153R.

\subsubsection{Leukocyte activation: M141R}

M141R is a membrane-associated protein which shares significant amino acid similarity to the family of cellular CD200 (OX-2) proteins, responsible for regulating the activities of myeloid lineage cells [4]. A number of features present in cellular CD200/OX-2 are also found in M141R, including the $\mathrm{C}$-terminal transmembrane domain, two highly conserved cysteine residues involved in the formation of the V-like immunoglobin domain and several critical residues invariably conserved in immunoglobin domains [11]. An increased level of IFN- $\gamma$ was observed when peripheral blood mononuclear cells purified from rabbits infected with MV deficient in the M141L gene (vMyx141KO) were activated in vitro [12]. Cultured rabbit cell lines infected with vMyx141KO showed no differences in growth or replication kinetics in comparison to the wild-type virus, however, M141R is essential for the development of myxomatosis in susceptible rabbits [12]. All rabbits infected with the M141R-knockout virus completely recovered with only mild signs of disease progression and all were completely protected from myxomatosis when rechallenged with the wild-type virus [12]. In the absence of M141R, a dramatic increase in the recruitment and activation of monocytes/macrophages and lymphocytes with the capacity to express high levels of the virotoxic compound nitric oxide was observed in lymphoid organs infected with MV [12]. Additionally, M141R was shown to reduce T-cell activation levels in lymph 
nodes and inhibit the ability of circulating T-cells to respond to T-cell antigenindependent activation [12]. In conclusion, M141R is essential for complete pathogenesis of MV and functions to inhibit tissue macrophages by reducing their ability to antigenically prime lymphocytes and possibly provides anergic signals to $\mathrm{T}$ cells directly.

\subsubsection{Leukocyte activation: $M 128 L$}

The membrane-associated protein M128L of MV is 218 amino acids in length, predicted to have a molecular mass of $32 \mathrm{kDa}$ and is predicted to function as an immunoregulator [11, 13]. M128L shares significant amino acid homology to the cellular CD47 protein (integrin-associated protein, or IAP), a well documented regulator of the vertebrate immune response which exerts multiple functions on various immune cell types [99]. A number of key features present in CD47 proteins are also present in $\mathrm{M} 128 \mathrm{~L}$, including an N-terminal signal sequence, a single predicted transmembrane domain and a short cytoplasmic tail [13]. The classical immunoglobulin-like domain is not predicted to be present in M128L; however, there is significant conservation of cystine residues and flanking amino acids that map to the CD47 immunoglobulin boundary domain [11]. M128L is fully dispensable for virus replication and infection in vitro and the vMyx $128 \mathrm{KO}$ showed no obvious differences in growth or replication kinetics when compared to the wild-type MV [13]. Early stages of viral disease progression were evident when rabbits were infected with vMyx128KO virus, however after day seven post infection signs of reduced virulence were observed. All rabbits made a complete recovery from viral infection and when re-challenged with wild type MV, they were found to be completely protected from myxomatosis [13]. Histological studies identified an increase in the activation and/or recruitment of iNOS ${ }^{+}$cells to the site of infection and in the lymphoid tissues during infection [13]. In conclusion, M128L is a novel CD47-like immunomodulatory gene and plays a critical role in the pathogenesis of MV by inhibiting the activation of myeloid-lineage cells.

\subsubsection{Leukocyte activation: Myxoma Nuclear Factor (M150R)}

MV encodes a number of ankyrincontaining proteins including the gene M150R [11], which has a total of nine ankyrin repeats (ANK), with the eighth having a close similarity to the nuclear localization signal-containing ANK of I$\kappa \mathrm{B} \alpha$ [14]. The protein I- $\kappa \mathrm{B}$ functionally binds to the transcription factor NF- $\mathrm{KB}$ to form an inactive I- $\kappa \mathrm{B} / \mathrm{NF}-\kappa \mathrm{B}$ complex which sequesters NF- $\mathrm{KB}$ in the cytosol, inhibiting its activity $[3,7,17,33]$. In cells treated with TNF, both M150R and NF-kB co-localized to the nucleus and therefore the protein was named myxoma nuclear factor (MNF) [14]. In vivo studies have demonstrated that MNF is a critical virulence factor for the development of myxomatosis in susceptible rabbits. In contrast to rabbits infected with wild-type MV, only mild signs of virus infection were observed in rabbits infected with the MNF knockout virus [14]. These particular rabbits fully recovered within 21 days post infection and when infected with the wild-type virus, were resistant to developing myxomatosis. In the absence of MNF, an increase in the inflammatory process was observed at the site of virus infection suggesting that MNF inhibits the NF- $\mathrm{kB}$-induced proinflammatory pathways [14].

\subsubsection{Leukocyte activation: Serp-3}

The MV genome encodes a third serpin protein, Serp-3, which contains a 
conserved serpin motif but lacks the significant sequence homology present in most cellular and viral serpins. Serp-3 is present in a single copy and the gene is located near the right TIR and encodes a protein with a molecular mass of approximately $30 \mathrm{kDa}$. Serp-3 is not essential for viral replication in vitro nor in vivo [36]. MV deficient in Serp-3 showed no defects in the ability to infect and replicate in either rabbit fibroblasts or $\mathrm{CD}^{+}{ }^{+} \mathrm{T}$-cell lines. Histological studies of rabbits infected with the knockout virus identified an increase in the inflammatory response and the lack of secondary myxomas present in the lymph nodes [36], resulting in dramatically attenuated virulence in vivo, reflected by the decrease in mortality rate of virus infected rabbits. Serp-3 represents a critical virulence factor for MV and probably acts in synergy with other viral proteins [36].

\subsubsection{Leukocyte activation: $M 13 L$}

The MV-encoded M13L gene is a putative immunomodulator containing a PYRIN domain (PYD) which is characteristic of the PYD superfamily of apoptosis and inflammatory regulators [43]. M13L was shown to colocalize and interact with the ASC-1 component of the host inflammasome, modulating the activation of caspase- 1 activity and processing of IL-1 $\beta$ and IL-18. In the absence of M13L, virus-infected rabbits did not develop myxomatosis despite enhanced acute inflammatory response to infection [43]. Disruption of the M13L gene also severely attenuated viral replication in cultured rabbit lymphocytes, yet replication in rabbit fibroblasts was comparable to that of the wild-type MV. Reduced virulence of the M13L knockout virus can be attributed to the inability of the virus to infect lymphocytes, thus inhibiting virus spread and dissemination from primary sites of infection. The role of M13L in manipulating the an- tiviral response of the host during infection is critical for virus replication and therefore $\mathrm{M} 13 \mathrm{~L}$ is a critical immunomodulatory protein for the development of myxomatosis [43].

\subsubsection{Leukocyte activation: M153R}

The M153R open reading frame of MV encodes the protein, MV leukemiaassociated protein (MV-LAP). M153R is an endoplasmic reticulum (ER)-resident and is characterized by an amino-terminal PHD/LAP motif and two centrally located transmembrane domains. MV-LAP was demonstrated to promote the downregulation of both surface MHC-I [37] and the T-cell co-receptor molecule CD4 by targeting them for degradation within the lysosomes [59]. Successful restoration of CD4 surface expression was achieved through over-expression of Hrs, a ubiquitin interaction motif-containing protein that sorts ubiquitinated proteins into endosomes. In addition, the purified PHD/LAP zinc finger of MV-LAP was demonstrated to be a critical factor in the formation of multi-ubiquitin adducts in vitro [59]. Rabbits infected with an MV-LAP mutant virus suffered moderate to severe respiratory infection, however experienced a higher rate of recovery in contrast to rabbits infected with wild-type MV [37]. Therefore MVLAP is a virulence factor which functions as a membrane-bound ubiquitin ligase, is an immune evasion mechanism that targets host cell immune receptors.

\section{PREVENTION, CONTROL AND VACCINATION}

When MV was intentionally introduced into the feral rabbit population in Australia in 1950, the biological control method 
failed because of a combination of increased host resistance and a genetic attenuation of field virus strains $[9,46]$. A head-to-head comparison of the Standard Laboratory Strain (SLS) and the attenuated Urraria (Ur) strain in susceptible and resistant rabbits indicated that MV replicates in cells that mediate the immune response; i.e. dendritic cells in the skin and T cells in the lymph node [9]. Infection with SLS resulted in far more lymphocyte depletion in rabbits than the Ur strain, and the less virulent Ur strain had a more robust inflammatory response consisting primarily of mononuclear cells while the more virulent SLS strain had an infiltrate of primarily polymorphonuclear cells [9]. The use of resistant rabbit populations also had a significant effect on the immune response to both viruses, suggesting that modeling this infection in fully naive laboratory rabbits provides only a starting point to understand the dynamics of $\mathrm{MV} /$ rabbit co-evolution since 1950.

In areas of the world where MV is endemic, control of virus spread among the rabbit population is critical to prevent outbreaks. In many cases, proper screening to exclude arthropod vectors such as mosquitoes and fleas is sufficient. In addition, the quarantine of new rabbits, as well as any sick rabbits, is necessary to effectively contain new outbreaks. The use of the closely related Shope Fibroma virus as a vaccine strain has yielded variable results, yet is generally effective [29]. In addition, a live attenuated form of MV, designated MSD strain, has been used as a vaccine strain. Immunization of rabbits results in a mild cutaneous reaction followed by immunity for approximately 9 months [81]. Serial passage of this virus in rabbit kidney cultures has further attenuated the virus without sacrificing its immunity and has been designated MSD/B [41]. In addition, the live attenuated vaccine designated SG33 is a vaccine that is currently used in France, Belgium and Italy. Inoc- ulation also results in a mild cutaneous reaction followed by immunity that lasted from 4 days post infection to over 10 months [82].

In addition to these strains, deletions of host range genes that have been identified to date from MV [66] would make excellent candidates for vaccines. Studies that have selectively deleted such genes have found no reduction in their in vitro replication levels, yet a severe defect in their ability to cause disease in rabbits (Tab. I). This has been shown as a proof of principle in studies where genes such as M-T5 have been selectively deleted [73]. Rabbits injected with the M-T5 knock out virus not only had very little clinical signs of myxomatosis, they were also protected from challenge with wild type MV [73]. Such attenuated viruses lacking host range genes would make excellent vaccine candidates, yet comprehensive studies into their effectiveness are needed since vaccines have yet to be completed.

To date, MV has been shown not to be able to infect any other vertebrate family besides lagomorphs in vivo; including day old mice [1], cats [63], and humans [40]. However, reports have indicated that MV can infect non-lagomorph cells in vitro; including squirrels, guinea pigs and primate kidney cells $[16,97]$. MV also replicated in guinea pig sarcoma cell lines in vitro, as well as in vivo [2]. A recent report has indicated that this virus exhibits a natural tropism for many human tumor cells [93], indicating that this virus could be used as a therapy in cancer treatment. Studies in a mouse model of glioma has shown that this virus is quite effective in infecting tumor tissue in vivo and effectively 'cured' mice from these brain tumors [56]. These studies have fostered enthusiasm in the prospect of using this virus clinically to treat human cancers [66]. In this case, special considerations will have to be met to ensure the safety of both wild and cultivated rabbit populations. Currently, oncolytic MV is 
being studied with consideration to these issues, and the clinical oncolytic platform will likely be a recombinant MV that has reduced virulence in rabbits but the oncolytic capacity of the wild type virus.

\section{CONCLUSIONS}

The host/pathogen interaction between MV and $O$. cuniculus has been a successful model to study the interaction between systemic disease-causing poxviruses and their hosts. Careful genetic manipulation of the virus has allowed for a better understanding of how these viruses elegantly subvert the host immune system through mimicry, stealth and avoidance. The result, however, is a devastating immune suppression in the host, leading to an immune based pathology and supervening bacterial infections that quickly overwhelm and kill the host. Initially proposed as a biological control mechanism, the introduction of MV into wild European rabbit populations has resulted in devastating outbreaks, but the subsequent co-evolution of both the host and virus has established a new, and still-evolving, equilibrium of morbidity and mortality in the wild. However, the popularity of domesticated European rabbits has increased concerns in the possibility of MV outbreaks. With our current understanding of the pathogenesis of MV infection, it should be feasible to develop better immunization strategies to combat infection in domesticated animals. In addition, with the possibility of using this virus in humans as a cancer therapy, vaccination of any animals in contact with patients, particularly companion animals, becomes increasingly important.

\section{ACKNOWLEDGEMENTS}

M.M. Stanford is supported by a Postdoctoral Fellowship provided by the Pamela Greenaway Kohlmeier Translational Breast Cancer
Research Unit of the London Regional Cancer Program. G. McFadden holds a Canada Research Chair in Molecular Virology and is an International Scholar of The Howard Hughes Medical Institute.

\section{REFERENCES}

[1] Andrewes C.H., Harisijades S., Propagation of myxoma virus in one-day old mice, Br. J. Exp. Pathol. (1955) 36:18-21.

[2] Andrewes C.H., Chaproniere D.M., Propagation of rabbit myxoma and fibroma viruses in a guinea pig sarcoma, Virology (1957) 4:346-350.

[3] Baeuerle P.A., IкB-NF-кB structures: at the interface of inflammation control, Cell (1998) 95:729-731.

[4] Barclay A.N., Wright G.J., Brooke G., Brown M.H., CD200 and membrane protein interactions in the control of myeloid cells, Trends Immunol. (2002) 23:285-290.

[5] Barrett J.W., Cao J.X., Hota-Mitchell S., McFadden G., Immunomodulatory proteins of myxoma virus, Semin. Immunol. (2001) 13:73-84.

[6] Barry M., Hnatiuk S., Mossman K., Lee S.F., Boshkov L., McFadden G., The myxoma virus M-T4 gene encodes a novel RDEL-containing protein that is retained within the endoplasmic reticulum and is important for the productive infection of lymphocytes, Virology (1997) 239:360-377.

[7] Bates P.W., Miyamoto S., Expanded nuclear roles for IкBs, Sci. STKE (2004) 12:pe48.

[8] Best S.M., Collins S.V., Kerr P.J., Coevolution of host and virus: cellular localization of virus in myxoma virus infection of resistant and susceptible European rabbits, Virology (2000) 277:7691.

[9] Best S.M., Kerr P.J., Coevolution of host and virus: the pathogenesis of virulent and attenuated strains of myxoma virus in resistant and susceptible European rabbits, Virology (2000) 267:36-48.

[10] Boomker J.M., Luttikhuizen D.T., Veninga H., de Leij L.F., The T.H., de Haan A., van Luyn M.J., Harmsen M.C., The modulation of angiogenesis in the foreign body response by the poxviral protein M-T7, Biomaterials (2005) 26:4874-4881. 
[11] Cameron C., Hota-Mitchell S., Chen L., Barrett J., Cao J.X., Macaulay C., Willer D., Evans D., McFadden G., The complete DNA sequence of myxoma virus, Virology (1999) 264:298-318.

[12] Cameron C.M., Barrett J.W., Liu L., Lucas A.R., McFadden G., Myxoma virus M141R expresses a viral CD200 (vOX-2) that is responsible for down-regulation of macrophage and T-cell activation in vivo, $\mathrm{J}$. Virol. (2005) 79:6052-6067.

[13] Cameron C.M., Barrett J.W., Mann M. Lucas A., McFadden G., Myxoma virus M128L is expressed as a cell surface CD47like virulence factor that contributes to the downregulation of macrophage activation in vivo, Virology (2005) 337:55-67.

[14] Camus-Bouclainville C., Fiette L., Bouchiha S., Pignolet B., Counor D., Filipe C., Gelfi J., Messud-Petit F., A virulence factor of myxoma virus colocalizes with $\mathrm{NF}-\kappa \mathrm{B}$ in the nucleus and interferes with inflammation, J. Virol. (2004) 78:2510-2516.

[15] Carter G.C., Law M., Hollinshead M., Smith G.L., Entry of the vaccinia virus intracellular mature virion and its interactions with glycosaminoglycans, J. Gen. Virol. (2005) 86:1279-90.

[16] Chaproniere D.M., Andrewes C.H., Cultivation of rabbit myxoma and fibroma viruses in tissues of nonsusceptible hosts, Virology (1957) 4:351-365.

[17] Chen Z.J., Ubiquitin signalling in the NF$\kappa \mathrm{B}$ pathway, Nat. Cell Biol. (2005) 7:758765 .

[18] Chung C.S., Hsiao J.C., Chang Y.S., Chang W., A27L protein mediates vaccinia virus interaction with cell surface heparan sulfate, J. Virol. (1998) 72:1577-1585.

[19] Dai E., Guan H., Liu L., Little S., McFadden G., Vaziri S., Cao H., Ivanova I.A., Bocksch L., Lucas A., Serp-1, a viral anti-inflammatory serpin, regulates cellular serine proteinase and serpin responses to vascular injury, J. Biol. Chem. (2003) 278:18563-18572.

[20] DiGiacomo R.F., Mare C.J., Viral diseases, in: Manning P.J., Ringler D.H., Newcomer C.E. (Eds.), The biology of the laboratory rabbit, 2nd ed., Academic Press, San Diego, 1994, p. 171-183.

[21] Everett H., Barry M., Lee S.F., Sun X., Graham K., Stone J., Bleackley R.C., McFadden G., M11L: a novel mitochondria-localized protein of myxoma virus that blocks apoptosis of infected leukocytes, J. Exp. Med. (2000) 191:14871498.

[22] Everett H., McFadden G., Viral proteins and the mitochondrial apoptotic checkpoint, Cytokine Growth Factor Rev. (2001) 12:181-188.

[23] Everett H., McFadden G., Viruses and apoptosis: meddling with mitochondria, Virology (2001) 288:1-7.

[24] Everett H., Barry M., Sun X., Lee S.F., Frantz C., Berthiaume L.G., McFadden G., Bleackley R.C., The myxoma poxvirus protein, M11L, prevents apoptosis by direct interaction with the mitochondrial permeability transition pore, J. Exp. Med. (2002) 196:1127-1139.

[25] Everett H., McFadden G., Poxviruses and apoptosis: a time to die, Curr. Opin. Microbiol. (2002) 5:395-402.

[26] Fenner F., Changes in the mortality-rate due to myxomatosis in the Australian wild rabbit, Nature (1953) 172:228-230.

[27] Fenner F., Woodroofe G.M., The pathogenesis of infectious myxomatosis; the mechanism of infection and the immunological response in the European rabbit (Oryctolagus cuniculus), Br. J. Exp. Pathol. (1953) 34:400-411.

[28] Fenner F., Marshall I.D., A comparison of the virulence for European rabbits (Oryctolagus cuniculus) of strains of myxoma virus recovered in the field in Australia, Europe and America, J. Hyg. (Lond.) (1957) 5:149-191.

[29] Fenner F., Ratcliffe F., Myxomatosis, University Press, Cambridge, 1965.

[30] Fenner F., The Florey lecture, 1983, Biological control, as exemplified by smallpox eradication and myxomatosis, Proc. R. Soc. Lond. B Biol. Sci. (1983) 218:259285 .

[31] Fenner F., Adventures with poxviruses of vertebrates, FEMS Microbiol. Rev. (2000) 24:123-133.

[32] Fields B.N., Knipe D.M., Howley P.M., Griffin D.E., Fields' virology, 4th ed., Lippincott Williams \& Wilkins, Philadelphia, 2001.

[33] Flohe L., Brigelius-Flohe R., Saliou C., Traber M.G., Packer L., Redox regulation of NF- $\kappa \mathrm{B}$ activation, Free Radic. Biol. Med. (1997) 22:1115-1126.

[34] Garon C.F., Barbosa E., Moss B., Visualization of an inverted terminal 
repetition in vaccinia virus DNA, Proc. Natl. Acad. Sci. USA (1978) 75:48634867.

[35] Graham K.A., Lalani A.S., Macen J.L., Ness T.L., Barry M., Liu L.Y., Lucas A., Clark-Lewis I., Moyer R.W., McFadden G., The T1/35kDa family of poxvirus-secreted proteins bind chemokines and modulate leukocyte influx into virus-infected tissues, Virology (1997) 229:12-24.

[36] Guerin J.L., Gelfi J., Camus C., Delverdier M., Whisstock J.C., Amardeihl M.F., Py R., Bertagnoli S., Messud-Petit F., Characterization and functional analysis of Serp3: a novel myxoma virus-encoded serpin involved in virulence, J. Gen. Virol. (2001) 82:1407-1417.

[37] Guerin J.L., Gelfi J., Boullier S., Delverdier M., Bellanger F.A., Bertagnoli S., Drexler I., Sutter G., Messud-Petit F., Myxoma virus leukemia-associated protein is responsible for major histocompatibility complex class I and Fas-CD95 downregulation and defines scrapins, a new group of surface cellular receptor abductor proteins, J. Virol. (2002) 76:2912-2923.

[38] Haga I.R., Bowie A.G., Evasion of innate immunity by vaccinia virus, Parasitology Suppl. (2005) 130:S11-25.

[39] Hnatiuk S., Barry M., Zeng W., Liu L., Lucas A., Percy D., McFadden G., Role of the C-terminal RDEL motif of the myxoma virus M-T4 protein in terms of apoptosis regulation and viral pathogenesis, Virology (1999) 263:290-306.

[40] Jackson E.W., Dorn C.R., Saito J.K., McKercher D.G., Absence of serological evidence of myxoma virus infection in humans exposed during an outbreak of myxomatosis, Nature (1966) 211:313-314.

[41] Jiran E., Sladka M., Kunstyr I., Myxomatosis of rabbits - study of virus modification, Zentralbl. Veterinarmed. B (1970) 17:418-428.

[42] Johnston J.B., McFadden G., Poxvirus immunomodulatory strategies: current perspectives, J. Virol. (2003) 77:6093-6100.

[43] Johnston J.B., Barrett J.W., Nazarian S.H., Goodwin M., Ricuttio D., Wang G., McFadden G., A poxvirus-encoded pyrin domain protein interacts with $\mathrm{ASC}-1$ to inhibit host inflammatory and apoptotic responses to infection, Immunity (2005) 23:587-598.

[44] Johnston J.B., Wang G., Barrett J.W., Nazarian S.H., Colwill K., Moran M.,
McFadden G., Myxoma virus M-T5 protects infected cells from the stress of cell cycle arrest through its interaction with host cell cullin-1, J. Virol. (2005) 79:1075010763.

[45] Kerr J.F., Wyllie A.H., Currie A.R., Apoptosis: a basic biological phenomenon with wide-ranging implications in tissue kinetics, Br. J. Cancer (1972) 26:239-257.

[46] Kerr P.J., Best S.M., Myxoma virus in rabbits, Rev. Sci. Tech. (1998) 17:256-268.

[47] Kerr P., McFadden G., Immune responses to myxoma virus, Viral Immunol. (2002) 15:229-246.

[48] Krogstad A.P., Simpson J.E., Korte S.W., Viral diseases of the rabbit, Vet. Clin. North Am. Exot. Anim. Pract. (2005) 8:123-138.

[49] Lalani A.S., Graham K., Mossman K., Rajarathnam K., Clark-Lewis I., Kelvin D., McFadden G., The purified myxoma virus gamma interferon receptor homolog M-T7 interacts with the heparin-binding domains of chemokines, J. Virol. (1997) 71:43564363.

[50] Lalani A.S., McFadden G., Secreted poxvirus chemokine binding proteins, J. Leukoc. Biol. (1997) 62:570-576.

[51] Lalani A.S., Ness T.L., Singh R., Harrison J.K., Seet B.T., Kelvin D.J., McFadden G., Moyer R.W., Functional comparisons among members of the poxvirus $T 1 / 35 \mathrm{kDa}$ family of soluble CC-chemokine inhibitor glycoproteins, Virology (1998) 250:173184.

[52] Lalani A.S., Masters J., Graham K., Liu L., Lucas A., McFadden G., Role of the myxoma virus soluble CC-chemokine inhibitor glycoprotein, M-T1, during myxoma virus pathogenesis, Virology (1999) 256:233-245.

[53] Lomas D.A., Evans D.L., Upton C., McFadden G., Carrell R.W., Inhibition of plasmin, urokinase, tissue plasminogen activator, and $\mathrm{C} 1 \mathrm{~S}$ by a myxoma virus serine proteinase inhibitor, J. Biol. Chem. (1993) 268:516-521.

[54] Lucas A., McFadden G., Secreted immunomodulatory viral proteins as novel biotherapeutics, J. Immunol. (2004) 173:4765-4774.

[55] Lucas A., McIvor D., McFadden G., Virusencoded chemokine modulators as novel anti-inflammatory reagents, Chemokine Biology - Basic Research and Clinical Application, Vol. 1, 2006, pp. 165-182. 
[56] Lun X., Yang W., Alain T., Shi Z.Q., Muzik H., Barrett J.W., McFadden G., Bell J., Hamilton M.G., Senger D.L., Forsyth P.A., Myxoma virus is a novel oncolytic virus with significant antitumor activity against experimental human gliomas, Cancer Res. (2005) 65:9982-9990.

[57] Macen J.L., Upton C., Nation N., McFadden G., SERP1, a serine proteinase inhibitor encoded by myxoma virus, is a secreted glycoprotein that interferes with inflammation, Virology (1993) 195:348-363.

[58] Macen J.L., Graham K.A., Lee S.F., Schreiber M., Boshkov L.K., McFadden G., Expression of the myxoma virus tumor necrosis factor receptor homologue and $\mathrm{M} 11 \mathrm{~L}$ genes is required to prevent virus-induced apoptosis in infected rabbit T lymphocytes, Virology (1996) 218:232237.

[59] Mansouri M., Bartee E., Gouveia K., Hovey Nerenberg B.T., Barrett J., Thomas L., Thomas G., McFadden G., Fruh K., The PHD/LAP-domain protein M153R of myxomavirus is a ubiquitin ligase that induces the rapid internalization and lysosomal destruction of CD4, J. Virol. (2003) 77:14271440 .

[60] Marlier D., Vindevogel H., Poxless myxomatosis - Isolation of three strains in Belgium, Ann. Med. Vet. (1996) 140:343346.

[61] Marlier D., Mainil J., Sulon J., Beckers J.F., Linden A., Vindevogel H., Study of the virulence of five strains of amyxomatous myxoma virus in crossbred New Zealand White/Californian conventional rabbits, with evidence of long-term testicular infection in recovered animals, J. Comp. Pathol. (2000) 122:101-113.

[62] Marlier D., Mainil J., Linde A., Vindevogel H., Infectious agents associated with rabbit pneumonia: isolation of amyxomatous myxoma virus strains, Vet. J. (2000) 159:171-178.

[63] McCabe V.J., Tarpey I., Spibey N., Vaccination of cats with an attenuated recombinant myxoma virus expressing feline calicivirus capsid protein, Vaccine (2002) 20:2454-2462.

[64] McFadden G., Graham K., Ellison K., Barry M., Macen J., Schreiber M., Mossman K., Nash P., Lalani A., Everett H., Interruption of cytokine networks by poxviruses: lessons from myxoma virus, J. Leukoc. Biol. (1995) 57:731-738.
[65] McFadden G., Lalani A., Everett H., Nash P., Xu X., Virus-encoded receptors for cytokines and chemokines, Semin. Cell Dev. Biol. (1998) 9:359-368.

[66] McFadden G., Poxvirus tropism, Nat. Rev. Microbiol. (2005) 3:201-213.

[67] Messud-Petit F., Gelfi J., Delverdier M., Amardeilh M.F., Py R., Sutter G., Bertagnoli S., Serp2, an inhibitor of the interleukin-1 $\beta$-converting enzyme, is critical in the pathobiology of myxoma virus, J. Virol. (1998) 72:7830-7839.

[68] Moss B., Poxviridae: The Viruses and their replication, in: Fields B.N., Knipe D.M., Howley P.M., Griffin D.E. (Eds.), Fields' virology, 4th ed., Lippincott Williams \& Wilkins, Philadelphia, 2001, pp. 28492883.

[69] Moss B., Shisler J.L., Immunology 101 at poxvirus U: immune evasion genes, Semin. Immunol. (2001) 13:59-66.

[70] Moss B., Poxvirus entry and membrane fusion, Virology (2006) 344:48-54.

[71] Mossman K., Upton C., McFadden G., The myxoma virus-soluble interferon- $\gamma$ receptor homolog, M-T7, inhibits interferon-gamma in a species-specific manner, J. Biol. Chem. (1995) 270:3031-3038.

[72] Mossman K., Nation P., Macen J., Garbutt M., Lucas A., McFadden G., Myxoma virus M-T7, a secreted homolog of the interferongamma receptor, is a critical virulence factor for the development of myxomatosis in European rabbits, Virology (1996) 215:17-30.

[73] Mossman K., Lee S.F., Barry M., Boshkov L., McFadden G., Disruption of M-T5, a novel myxoma virus gene member of poxvirus host range superfamily, results in dramatic attenuation of myxomatosis in infected European rabbits, J. Virol. (1996) 70:4394-410.

[74] Nash P., Barrett J., Cao J.X., Hota-Mitchell S., Lalani A.S., Everett H., Xu X.M., Robichaud J., Hnatiuk S., Ainslie C., Seet B.T., McFadden G., Immunomodulation by viruses: the myxoma virus story, Immunol. Rev. (1999) 168:103-120.

[75] Nazarian S.H., McFadden G., Immune evasion by poxviruses, Future Medicine (2006) 1:123-132.

[76] Ng F.W., Nguyen M., Kwan T., Branton P.E., Nicholson D.W., Cromlish J.A., Shore G.C., p28 Bap31, a Bcl-2/Bcl-XLand procaspase-8-associated protein in the 
endoplasmic reticulum, J. Cell Biol. (1997) 139:327-338.

[77] Ng F.W., Shore G.C., Bcl-XL cooperatively associates with the Bap31 complex in the endoplasmic reticulum, dependent on procaspase- 8 and Ced-4 adaptor, J. Biol. Chem. (1998) 273:3140-3143.

[78] Opgenorth A., Graham K., Nation N. Strayer D., McFadden G., Deletion analysis of two tandemly arranged virulence genes in myxoma virus, M11L and myxoma growth factor, J. Virol. (1992) 66:4720 4731 .

[79] Opgenorth A., Nation N., Graham K., McFadden G., Transforming growth factor alpha, Shope fibroma growth factor, and vaccinia growth factor can replace myxoma growth factor in the induction of myxomatosis in rabbits, Virology (1993) 192:701-709.

[80] Petit F., Bertagnoli S., Gelfi J., Fassy F., Boucraut-Baralon C., Milon A. Characterization of a myxoma virusencoded serpin-like protein with activity against interleukin-1 $\beta$-converting enzyme, J. Virol. (1996) 70:5860-5866.

[81] Saito J.K., McKercher D.G., Castrucci G., Attenuation of the myxoma virus and use of the living attenuated virus as an immunizing agent for myxomatosis, J. Infect. Dis. (1964) 114:417-428

[82] Saurat P., Gilbert Y., Gagniere J.P., Étude d'une souche de virus myxomateux modifié, Rev. Med. Vet. (1978) 129:415-451.

[83] Schmelz M., Sodeik B., Ericsson M., Wolffe E.J., Shida H., Hiller G., Griffiths G., Assembly of vaccinia virus: the second wrapping cisterna is derived from the trans Golgi network, J. Virol. (1994) 68:130 147.

[84] Schreiber M., McFadden G., The myxoma virus TNF-receptor homologue (T2) inhibits tumor necrosis factor-alpha in a species-specific fashion, Virology (1994) 204:692-705.

[85] Schreiber M., McFadden G., Mutational analysis of the ligand-binding domain of M-T2 protein, the tumor necrosis factor receptor homologue of myxoma virus, J. Immunol. (1996) 157:4486-4495.

[86] Schreiber M., Rajarathnam K., McFadden G., Myxoma virus T2 protein, a tumor necrosis factor (TNF) receptor homolog, is secreted as a monomer and dimer that each bind rabbit TNFalpha, but the dimer is a more potent TNF inhibitor, J. Biol. Chem. (1996) 271:13333-13341.

[87] Seet B.T., Johnston J.B., Brunetti C.R., Barrett J.W., Everett H., Cameron C., Sypula J., Nazarian S.H., Lucas A., McFadden G., Poxviruses and immune evasion, Annu. Rev. Immunol. (2003) 21:377423.

[88] Smith G.L., Vanderplasschen A., Extracellular enveloped vaccinia virus. Entry, egress, and evasion, Adv. Exp. Med. Biol. (1998) 440:395-414.

[89] Smith G.L., Law M., The exit of vaccinia virus from infected cells, Virus Res. (2004) 106:189-197

[90] Smith S.A., Kotwal G.J., Virokines: novel immunomodulatory agents, Expert. Opin. Biol. Ther. (2001) 1:343-357.

[91] Stanford M.M., McFadden G., The "supervirus"? Lessons from IL-4-expressing poxviruses, Trends Immunol. (2005) 26:339-345.

[92] Su J., Wang G., Barrett J.W., Irvine T.S., Gao X., McFadden G., Myxoma virus M11L blocks apoptosis through inhibition of conformational activation of Bax at the mitochondria, J. Virol. (2006) 80:11401151.

[93] Sypula J., Wang F., Ma Y., Bell J., McFadden G., Myxoma virus tropism in human tumour cells, Gene Ther. Mol. Biol. (2004) 8:103-114

[94] Taylor J.M., Barry M., Near death experiences: poxvirus regulation of apoptotic death, Virology (2006) 344:139-150.

[95] Turner P.C., Sancho M.C., Thoennes S.R., Caputo A., Bleackley R.C., Moyer R.W., Myxoma virus Serp2 is a weak inhibitor of granzyme B and interleukin- $1 \beta$-converting enzyme in vitro and unlike CrmA cannot block apoptosis in cowpox virus-infected cells, J. Virol. (1999) 73:6394-6404.

[96] Upton C., Macen J.L., Wishart D.S., McFadden G., Myxoma virus and malignant rabbit fibroma virus encode a serpinlike protein important for virus virulence, Virology (1990) 179:618-631.

[97] Upton C., Macen J.L., Schreiber M., McFadden G., Myxoma virus expresses a secreted protein with homology to the tumor necrosis factor receptor gene family that contributes to viral virulence, Virology (1991) 184:370-382. 
[98] Upton C., Mossman K., McFadden G., Encoding of a homolog of the IFN- $\gamma$ receptor by myxoma virus, Science (1992) 258:1369-1372.

[99] Van Beek E.M., Cochrane F., Barclay A.N., van den Berg T.K., Signal regulatory proteins in the immune system, J. Immunol. (2005) 175:7781-7787.

[100] Van Eijl H., Hollinshead M., Rodger G., Zhang W.H., Smith G.L., The vaccinia virus F12L protein is associated with intracellular enveloped virus particles and is required for their egress to the cell surface, J. Gen. Virol. (2002) 83:195-207.

[101] Vanderplasschen A., Smith G.L., A novel virus binding assay using confocal microscopy: demonstration that the intracellular and extracellular vaccinia virions bind to different cellular receptors, J. Virol. (1997) 71:4032-4041.
[102] Vanderplasschen A., Hollinshead M., Smith G.L., Intracellular and extracellular vaccinia virions enter cells by different mechanisms, J. Gen. Virol. (1998) 79:877-887.

[103] Wang G., Barrett J.W., Nazarian S.H. Everett H., Gao X., Bleackley C., Colwill K., Moran M.F., McFadden G., Myxoma virus $\mathrm{M} 11 \mathrm{~L}$ prevents apoptosis through constitutive interaction with Bak, J. Virol. (2004) 78:7097-7111.

[104] Ward B.M., The longest micron; transporting poxviruses out of the cell, Cell. Microbiol. (2005) 7:1531-1538.

[105] Webb L.M., Alcami A., Virally encoded chemokine binding proteins, Mini Rev. Med. Chem. (2005) 5:833-848.

[106] Zuniga M.C., Lessons in detente or know thy host: the immunomodulatory gene products of myxoma virus, J. Biosci. (2003) 28:273-285. 